\title{
Optimization of biodiesel production from waste frying palm oil using definitive screening design
}

\author{
Y. Rajesh $^{1 *}$, Aditya Kolakoti ${ }^{2}$, B.G. Chandra Sheakar ${ }^{3}$, J. Bhargavi ${ }^{4}$ \\ ${ }^{1,2,3,4}$ Department of Mechanical Engineering, Anil Neerukonda Institute of Technology and Sciences(A), INDIA \\ "Corresponding Author: e-mail: rajraj1998@gmail.com, Tel +91-7993817945,
}

\begin{abstract}
Research on alternative fuels is increasing these days due to the fact that these fuels can be afforded without any climate-change aggravation. Biodiesel from different feed stocks has a potential to replace the existing diesel fuel, but the cost involved in the production of biodiesel is more. To mitigate the high production cost, low cost feed stocks of used cooking oils (UCO) can be used. As per the latest statistics approximately $198 \mathrm{MMT} / \mathrm{yr}$ of edible oil is used around the world. These UCO are dumped after usage which causes environmental imbalance. In this research an attempt was made to utilize the waste frying palm oil (WFPO) which was available in the college for biodiesel production. To maximize the biodiesel yield latest optimization technique of definitive screening design (DSD) was implemented. It was concluded that maximum yield of $96.23 \%$ was achieved at molar ratio of $6: 1$, reaction temperature of $55^{\circ} \mathrm{C}$ and the catalytic concentration of $1 \mathrm{wt} \%$. The fuel samples were tested for different physiochemical properties and fatty acid compositions. It was observed that the properties were within the limits of international standards. Hence, by using the WFPO the overall production cost was reduced and optimization by DSD enhanced the biodiesel yield.
\end{abstract}

Keywords: Waste fried palm biodiesel, optimization, definitive screening design, fatty acid composition, soap

DOI: http://dx.doi.org/10.4314/ijest.v11i2.4

\section{Introduction}

To improve the economy of any country energy plays a key role. Petroleum products are the major commercial source of energy across the world. In India the demand for the diesel is five times higher than petrol (Dhar et al., 2012; Kolakoti and Rao, 2015). As per the latest population reports, India needs to generate 4 to 5-fold more energy than the present. In order to meet the demand, one must rely on the commercial sources which are finite and they are in verge of depletion (Agarwal and Rajamanoharan, 2007). Apart from the availability of the fossil fuel, their applications in internal combustion engines also increase the air pollution levels by emitting harmful exhaust tail pipe emissions like NOx, CO, UHC, $\mathrm{CO}_{2}$ and smoke etc. (Modi et al., 2007; Talamala et al., 2016; Rao and Rao, 2017; Kolakoti and Rao, 2017c). To mitigate the challenges of exhaust emissions, biodiesel from edible and nonedible oils is best the possible solution. Researches and demonstrated project reveal that the alternative fuels from edible and non-edible oils can reduce the harmful exhaust emissions to a greater extent (Kalam et al., 2011). The unique properties in biodiesel can improve the combustion propensity (Demirbas, 2005), biodiesel acts as a best lubricant and the molecular oxygen presence helps in improved combustion with limited emissions (Kolakoti and Rao, 2017a). By implementing biodiesel in diesel engines will reduce the reliance on foreign oil products and increase the economy of a country like India. The raw oils which are used for the production of biodiesel possess high viscosity. This high viscosity can be reduced by following pyrolysis, thermal cracking, preheating and transesterification. Among the mentioned processes transesterification is a widely used method (Kolakoti and Rao, 2017b). During transesterification process several process parameters will influence the biodiesel yield some of them were catalytic concentration, methanol to oil ratio, reaction time and reaction temperature. Producing biodiesel from plant oils 
including the cost of catalysts, alcohol and processes will turn out to be more expensive than diesel, to overcome this problem cooking oils which are dumped after several uses, which are of no further use can be converted into biodiesel.

In order to achieve the maximum biodiesel yield with limited raw material cost and time, optimization techniques are most suitable (Wu et al., 1999; Vicente et al., 2007; Cavalcante et al. 2010). The advanced optimization technique of definitive screening design was implemented (DSD). The DSD is a new optimization technique in Minitab-18 it is similar to factorial design and it is more time efficient and it can determine the main effects and contributions of the factors early in the analysis. By implementing this optimization technique, the biodiesel yield can be improved, on the other hand the important contributing factors for biodiesel yield were also be analyzed.

\section{Materials and Methods}

\subsection{Materials}

Fried palm oil of 10 liters was collected from the different food courts, Methanol, Sodium hydroxide, Sulphur acid was purchased from the Sigma-Aldrich chemical company. Different sizes of glass beakers, RPM controlled electro-mechanical stirrer, Distilled water were used for the biodiesel production.

\subsection{Experimental procedure}

Waste frying palm oil (WFPO) which was collected from our college was first preheated and then filtered with surgical cotton to remove the dust and unwanted suspended particles. To reduce the high viscosity of the palm oil a widely used transesterification process was followed. In this transesterification process the exchange of organic group of esters with organic group of alcohol $\left(\mathrm{CH}_{3} \mathrm{OH}\right)$, which are catalyzed by addition of base catalyst $(\mathrm{NaOH})$ to form as methyl esters. Sodium hydroxide pellets of 4 grams were mixed with $90 \mathrm{ml}$ of methanol to form a methoxide solution and it was added in $500 \mathrm{ml}$ of esterified WFPO and the solution was maintained at desired reaction temperatures $\left(27^{\circ} \mathrm{C}\right.$ to $\left.55^{\circ} \mathrm{C}\right)$. After a period of time (60 to $\left.180 \mathrm{~min}\right)$ there will be a clear separation of glycerin and methyl ester, the heavy density glycerin gets settled in the bottom as shown in the Figure 1 was removed and the methyl esters was washed continuously with distilled water until a clear separation of oil and water appears as shown in the fig.2. The obtained fuel samples were tested for different physicochemical properties by following the international standards as shown in the Table 1. Biodiesel yield obtained from transesterification process depends on factors like reaction temperature, reaction time, molar ratio and catalytic concentration by variation in the amounts of these factors' biodiesel yield can be modified. In order to achieve the maximum yield, in our investigation definitive screening design in design of experiments was used for optimization of biodiesel for producing highest possible yield.

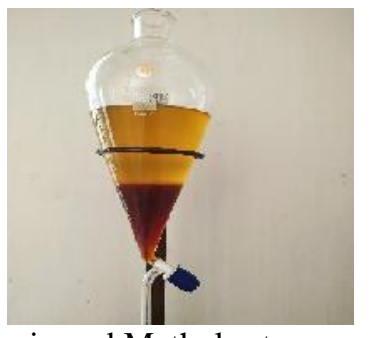

Figure 1. Glycerin and Methyl ester separation

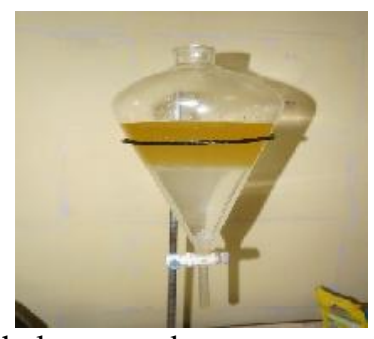

Figure 2. Methyl ester and water separation

Table 1. Characterization of WFPO methyl ester

\begin{tabular}{lllll}
\hline S.No & Properties & Diesel & WFPO & Standards \\
\hline 1 & Viscosity $(\mathrm{cSt})$ & 2.8 & 4.2 & ASTM-D445 \\
2 & Density $\left(\mathrm{kg} / \mathrm{m}^{3}\right)$ & 830 & 870 & ASTM-D1298 \\
3 & Flash point $\left({ }^{\circ} \mathrm{C}\right)$ & 62 & 145 & ASTM-D975 \\
4 & Cloud point $\left({ }^{\circ} \mathrm{C}\right)$ & -12 & -3 to 10 & ASTM-D975 \\
5 & Pour point $\left({ }^{\circ} \mathrm{C}\right)$ & -16 & -5 to 7 & ASTM-D975 \\
6 & Cetane number & 47 & 53 & ASTM-D4737 \\
7 & Calorific value $(\mathrm{MJ} / \mathrm{kg})$ & 44 & 38 & ASTM-D2382 \\
\hline
\end{tabular}

\subsection{Definitive Screening optimization}

Definitive screening design (DSD) is a new optimization technique in the Design of Experiment (DOE) MinTab-18. It identifies the most important factors early in the experimentation process. Definitive screening designs can fit 2-48 factors. This method identifies the important key parameters which influence the output for a given input. It also reduces the number of input parameters compared to other standard techniques like full factorial, response surface and mixture design etc. This technique is most suitable for minimum variable parameters; it also allows the user to restrict the input variable process parameter to a particular limit. Definitive screening is useful when the user wants to consider both linear and quadratic terms and to identify the 
most critical factors Due to the wide range of advantages in definitive screening technique in this research, we adopted a two-level fractional factorial design with three factors. The three contributing factors were molar ratio (A), catalytic concentration (B) and reaction temperature $(\mathrm{C})$ and their ranges are shown in the Table 2 . The catalytic concentration $(\mathrm{NaOH})$ was varied from 3.50 to 5.0, Molar ration (Methanol to oil ratio) $4: 1$ to $6: 1$ and the reaction temperature was varied from room temperature $\left(27^{\circ} \mathrm{C}\right)$ to methanol evaporation temperature $\left(55^{\circ} \mathrm{C}\right)$ and the catalytic concentration of 3 to 5 grams. (Catalytic concentration is the weight percent of catalyst taken to the amount of waste fried palm oil used i.e. 3.5 grams of $\mathrm{NaOH}$ in $500 \mathrm{ml}$ of oil is equal $(3.5 / 500) * 100$ $=0.7 \mathrm{wt} \%)$

Table 2. Process parameters and their ranges

\begin{tabular}{llll}
\hline S.No & Variable & Range Minimum & Range Maximum \\
\hline 1 & Reaction Temperature $\left({ }^{\circ} \mathrm{C}\right)$ & 27 & 55 \\
2 & Catalytic Concentration (grams) & 3.5 & 5 \\
3 & Molar Ratio & $4: 1$ & $6: 1$ \\
\hline
\end{tabular}

Table 3 represents the matrix for the three contributing factors generated by DSD and yield was chosen as a response. Based on the system generated matrix, 13 experiments were conducted and the response yield was obtained. The yield of the biodiesel is calculated from the Eq.1.

Yield $(\%)=$ Weight of biodiesel/Weight of raw oil

Table 3 Matrix of process parameters and their response yield

\begin{tabular}{lllll}
\hline Run No & Reaction Temperature & Catalytic Concentration & Molar Ratio & Yield (\%) \\
\hline 1 & 55 & 5 & $5: 1$ & 93.24 \\
2 & 27 & 4.25 & $4: 1$ & 84.97 \\
3 & 41 & 3.5 & $4: 1$ & 84.85 \\
4 & 41 & 4.25 & $5: 1$ & 88.32 \\
5 & 55 & 3.5 & $4: 1$ & 86.55 \\
6 & 27 & 3.5 & $5: 1$ & 86.72 \\
7 & 41 & 5 & $6: 1$ & 93.95 \\
8 & 27 & 5 & $6: 1$ & 93.15 \\
9 & 27 & 3.5 & $6: 1$ & 90.10 \\
10 & 27 & 5 & $4: 1$ & 86.79 \\
11 & 55 & 5 & $4: 1$ & 90.61 \\
12 & 55 & 3.5 & $6: 1$ & 93.82 \\
13 & 55 & 4.25 & $6: 1$ & 94.40 \\
\hline
\end{tabular}

\subsection{Analysis of Variance}

Analysis of variance (ANOVA) is based on an approach, in which the procedure uses a variance to predict whether the means are differentiable. It also measures the importance of contributing factors by comparing the response (Yield) variable at different levels. Based on the experimental yield matrix the response yield was analyzed and the ANOVA Table 4 was generated for the contributing factors.

Table 4. Analysis of Variance

\begin{tabular}{lllllll}
\hline S.No & Source & DF & Adj SS & Adj MS & F- Value & P-Value \\
\hline 1 & Model & 3 & 153.333 & 51.111 & 111.41 & 0.000 \\
2 & Linear & 3 & 153.333 & 51.111 & 111.41 & 0.000 \\
3 & Reaction Temperature & 1 & 28.527 & 28.527 & 62.18 & 0.000 \\
4 & Catalytic Concentration & 1 & 24.665 & 24.665 & 53.76 & 0.000 \\
5 & Molar Ratio & 1 & 100.141 & 100.141 & 218.27 & 0.000 \\
6 & Error & 9 & 4.129 & 0.459 & & \\
7 & Total & 12 & 157.462 & & & \\
\hline
\end{tabular}

The contribution of each factor can be found out by using $\mathrm{p}$ and $\mathrm{t}$ values, the lower the $\mathrm{p}$ value better the significance of the contributing factor, from the Table 5, the value of $\mathrm{p}$ can be found 0.000 in all the cases which indicates the design was very suitable, $t$ value indicates the individual contribution of each factor to the response. From the Table 5, it is clear that molar ratio has the highest contribution in the yield, the $t$ value of molar ratio is (14.77). 
Table 5. Definitive screening analysis

\begin{tabular}{lllllll}
\hline S.No & Term & Coef & SE Coef & T-Value & P-Value & VIF \\
\hline 1 & Constant & 89.806 & 0.188 & 478.05 & 0.000 & \\
2 & Reaction Temperature & 1.689 & 0.214 & 7.89 & 0.000 & 1.00 \\
3 & Catalytic Concentration & 1.571 & 0.214 & 7.33 & 0.000 & 1.00 \\
4 & Molar Ratio & 3.165 & 0.214 & 14.77 & 0.000 & 1.00 \\
\hline
\end{tabular}

In addition, Table 6 represents the Standard deviation (S) Coefficient of determination(R-sq) and adjust coefficient of determination(R-sq(adj)). S represents the standard deviation between data values and fitted values. Lower the $S$ values better the model describes the response. The R-sq represents the percentage of variation in the responses and it also determines how well the model fits the experimental data. Higher R-sq indicates that most of the variations in response can be explained, here R-sq $(97.38 \%)$ indicates that the model fits the data.

Table 6. R-sq values for the optimized model

\begin{tabular}{lllll}
\hline S.No & S & R-sq & R-sq (adj) & R-sq(pred) \\
\hline 1 & 0.677335 & $97.38 \%$ & $96.50 \%$ & $95.43 \%$ \\
\hline
\end{tabular}

\subsection{Pareto chart of standardized effects}

The Pareto chart gives the information about the absolute values of the standardized effects from maximum to minimum effect. The standardized effects test the null hypothesis. The chart also plots a reference line which indicates the effects that are statistically significant and it is denoted by alpha. From the fig. 3 all the three contributing factors cross the reference line which indicates that the all the three factors statically significant with $95 \%$ confidence and the null hypothesis can be rejected.

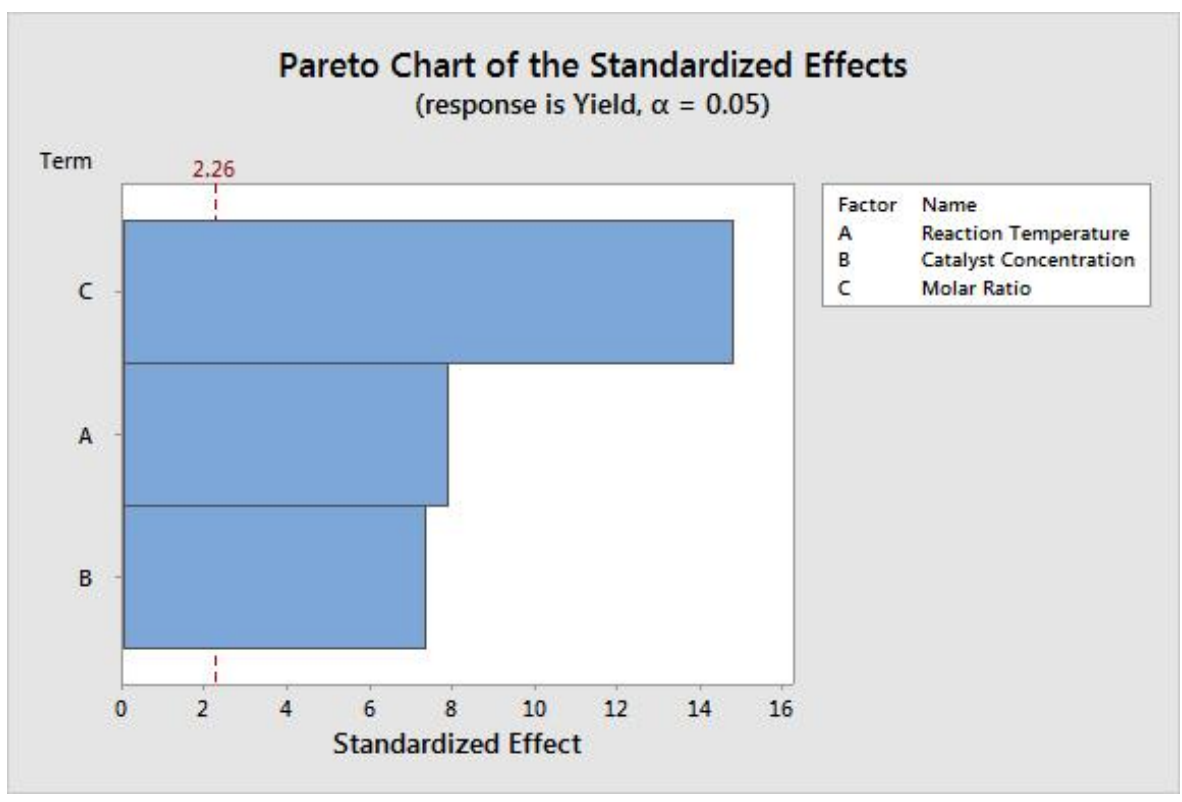

Figure 3. Pareto Chart

\section{Result and Discussions}

\subsection{Physicochemical properties}

Physicochemical properties of the biodiesel are gaining more importance, due to the fact, its increasing demand in worldwide. The properties of the biodiesel depend on the chemical compositions and fatty acid compositions. In this paper different physicochemical properties were measured by following international standards. Table 7 represents the different properties and their standards. Fatty acid compositions (FAC) in the biodiesel are the important properties which reveal the information of combustion propensity and exhaust emissions. In this research FAC were analyzed by gas chromatography. Table 7 represents the contribution of saturated and unsaturated FAC in the biodiesel. From the researchers (Kolakoti and Rao, 2017b) it is found that, the presence of unsaturated FAC level in the biodiesel will increase the formation of NOx and unburnt hydrocarbons. 
Table 7. Fatty acid composition by Gas chromatography

\begin{tabular}{llll}
\hline S.No & Composition & Saturated/Unsaturated & $\mathrm{Wt} \%$ \\
\hline 1 & Palmitic acid & Saturated & 22 \\
2 & Linoleic acid & Unsaturated & 52 \\
3 & Oleic acid & Unsaturated & 7 \\
4 & Myristic acid & Saturated & 4 \\
5 & Caprylic acid & Saturated & 3 \\
6 & Stearic acid & Saturated & 12 \\
\hline
\end{tabular}

The quality of combustion depends on the quality of the fuel, Cetane number $(\mathrm{CN})$ is known for the diesel quality index. In general, the $\mathrm{CN}$ for biodiesel is always greater than the conventional diesel fuel. The cost involved in determining the $\mathrm{CN}$ through experimental approach is high and sometimes even less accurate due to the experimental errors. In order to overcome the experimental cost and errors different methods have been proposed to predict the CN. Bamgboye and Hansen (2008) suggested that, with the FAC it is possible to predict the CN. Equation (2) represent the relation between biodiesel FAC and CN.

Cetane number $=\mathrm{K}+\mathrm{ax}_{2}+\mathrm{bx_{2 }}+\mathrm{cx}_{3}+\mathrm{dx}_{4}+\mathrm{ex}_{5}+\mathrm{fx}_{6}+\mathrm{gx}_{7}+\mathrm{hx_{8 }}{ }^{-}$

(Bamgboye and Hansen (2008)

$$
61.1+0.088 \mathrm{X}_{2}+0.133 \mathrm{X}_{3}+0.152 \mathrm{X}_{4}-0.101 \mathrm{X}_{5}-0.039 \mathrm{X}_{6}-0.243 \mathrm{X}_{7}-0.395 \mathrm{X}_{8}
$$

where $\mathrm{K}, \mathrm{a}, \mathrm{b}, \mathrm{c}, \mathrm{d}, \mathrm{e}, \mathrm{f}, \mathrm{g}, \mathrm{h}$ are constants taken from regression analysis and $\mathrm{X}_{1}$ to $\mathrm{X}_{8}$ are the \% of FAC

For Waste Fried Palm Oil Methyl Ester (WFPOME),

Cetane number $=61.1+0.352+2.926+1.848-0.273-12.636=\mathbf{5 3 . 3 2}$

\subsection{Maximum Yield}

Biodiesel yield is defined as the ratio of weight of produced biodiesel to weight of raw oil. From the response Table 3, the optimum values were generated using response optimizer in DSD and the optimum values were found as reaction temperature 55, catalytic concentration 5 and the molar ratio as 6 as shown in optimization plot. 4 a \& b and in the Table. 8

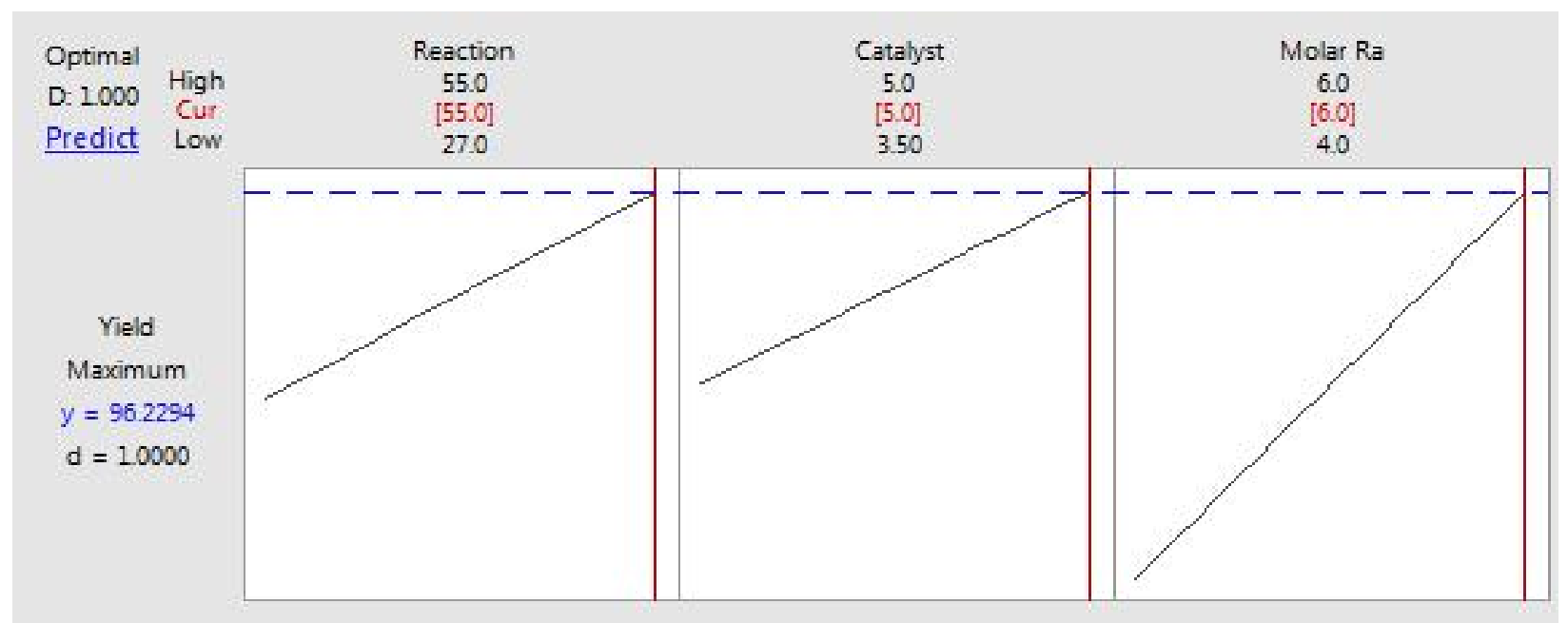

Figure 4(A). Main effects plots for yield. 


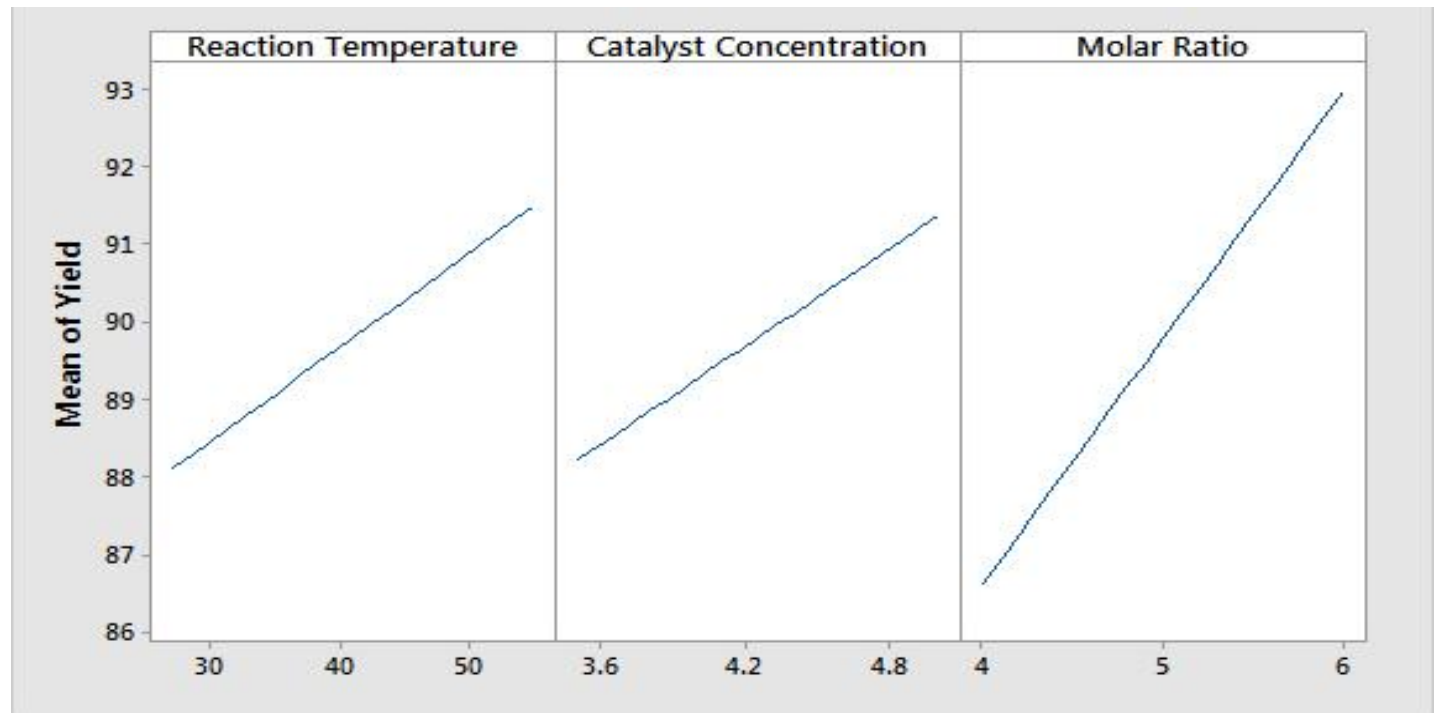

Figure 4 (B). Main effects plots for yield.

Table 8. Optimum contributing factors

\begin{tabular}{lll}
\hline S.No & Variable & Setting \\
\hline 1 & Reaction Temperature & 55 \\
2 & Catalytic Concentration & 5 \\
3 & Molar Ratio & 6 \\
\hline
\end{tabular}

Regression equation was generated for the three factors and optimum yield was found out from the regression equation (Eq.2) by substituting the optimum values in the equation a maximum yield of $\mathbf{9 6 . 2 3 0}$ was obtained.

Yield $=60.14+0.1206$ R.T + 2.093 C.C+ 3.165 M.R $=96.230$

Where

R. T= Reaction Time

C.C $=$ Catalytic Concentration

M.R= Molar Ratio

\subsection{Effect of molar ratio on yield}

Molar ratio (methanol to oil) plays a vital role in the transesterification process. The yield of the methyl esters can be increased with increasing molar ratio to an optimum level. This may be due to high mass ratio of reactants, which increases the contact between the methanol and the oil molecules. If the percentage of alcohol (methanol) increases than the desired for a given mixture then the polarity of the mixture will increase there by increasing the solubility of the glycerol back into the ester phase which ultimately reduces the biodiesel yield. From the figures $5 \& 6$ of contour and surface plots it is clear that, more than $94 \%$ of methyl ester yield can be acclaimed at a molar ratio (M.R) of 6.0, catalytic concentration (C.C) of 5 at a constant temperature (C.T) of $41^{0} \mathrm{C}$.

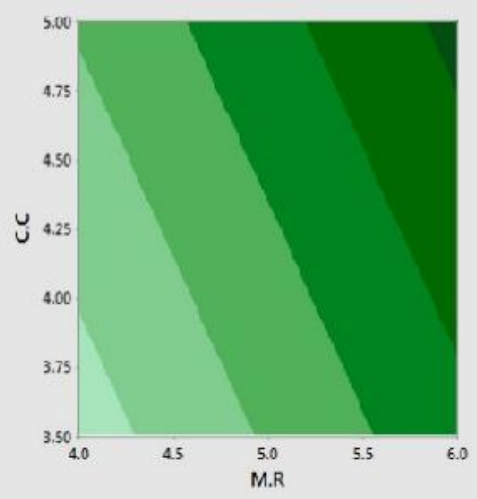

Figure 5. Contour Plot for max yield

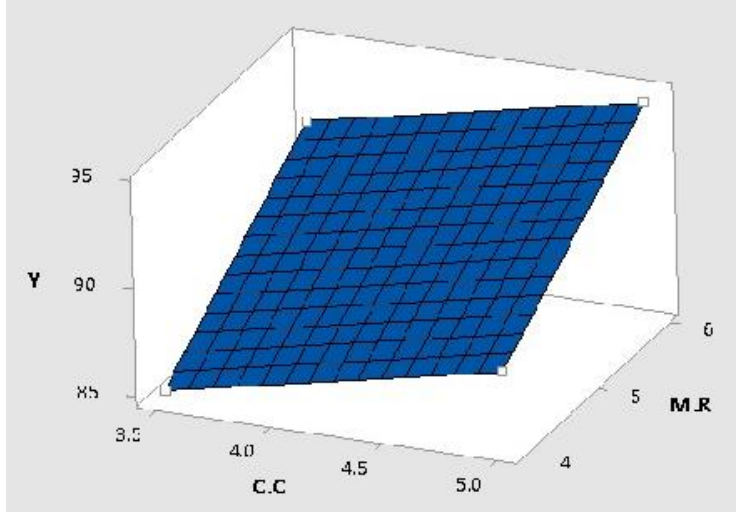

Figure 6. Surface Plot for max yield 


\subsection{Effect of reaction temperature on yield}

To achieve maximum yield, reaction temperature and the presence of alcohol in a given mixture are very important. At high temperature $\left(<62^{\circ} \mathrm{C}\right)$ the rate of reaction in the mixture is more and the contributing yield will increase. If the reaction temperature exceeds the boiling point of methanol $\left(64.5^{\circ} \mathrm{C}\right)$ then evaporation of methanol takes place there by decreasing the volume of the mixture which will result in decrease in the biodiesel yield. From the figures $7 \& 8$ a maximum yield of $94 \%$ is achieved at a reaction temperature of $55^{\circ} \mathrm{C}$, molar ratio of 6 by maintaining a constant catalytic concentration of 4.25 .

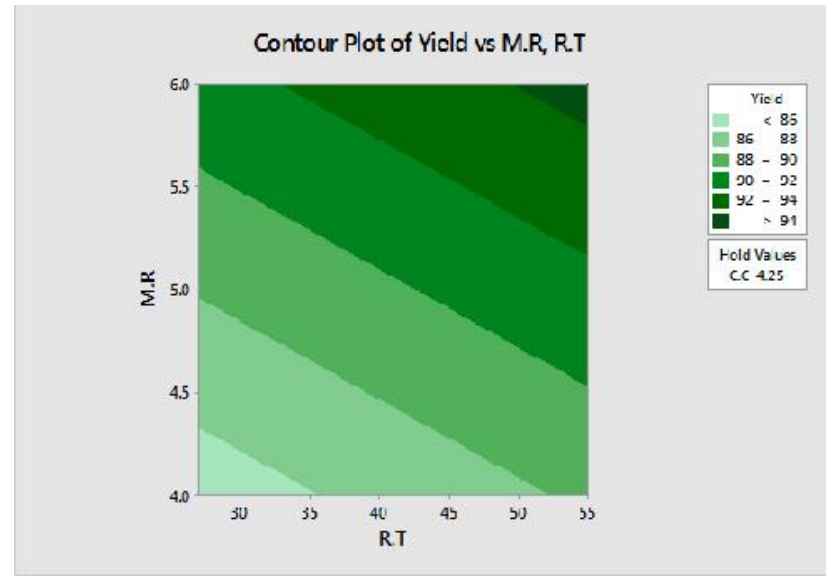

Figure 7. Contour Plot for max yield

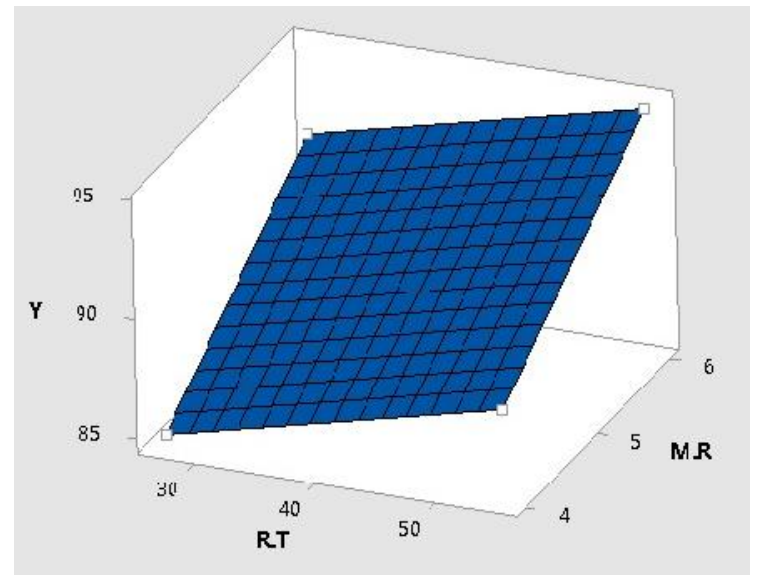

Figure 8. Surface Plot for max yield

\subsection{Effect of Catalytic concentration on yield}

Different catalysts were used for the production of methyl esters some of them were sodium hydroxide $(\mathrm{NaOH})$ and potassium hydroxide $(\mathrm{KOH})$. Due to the wide availability and for better biodiesel yield sodium hydroxide is used as catalyst. In this present analysis 3.5 to 5 grams of $\mathrm{NaOH}$ is used in the transesterification process. Figures $9 \& 10$ represents the contour and surface plots for the WFPO biodiesel yield at different catalytic concentration and different reaction temperature. From the figures $10 \& 11$ it is clear that by increasing the CC (4.75 to 5 grams) and the RT $\left(47\right.$ to $\left.55^{\circ} \mathrm{C}\right)$ simultaneously the maximum yield (93\%) of the WFPO biodiesel is achieved by maintaining a constant molar ratio of 5 .

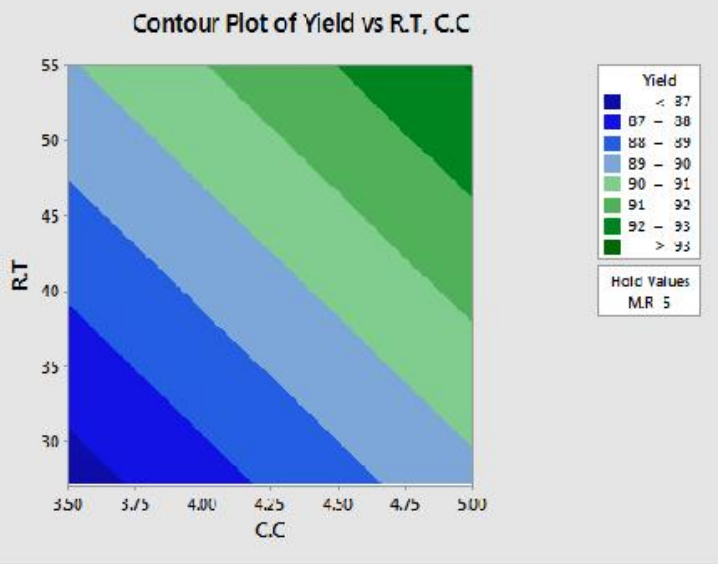

Figure 9. Contour Plot for max yield

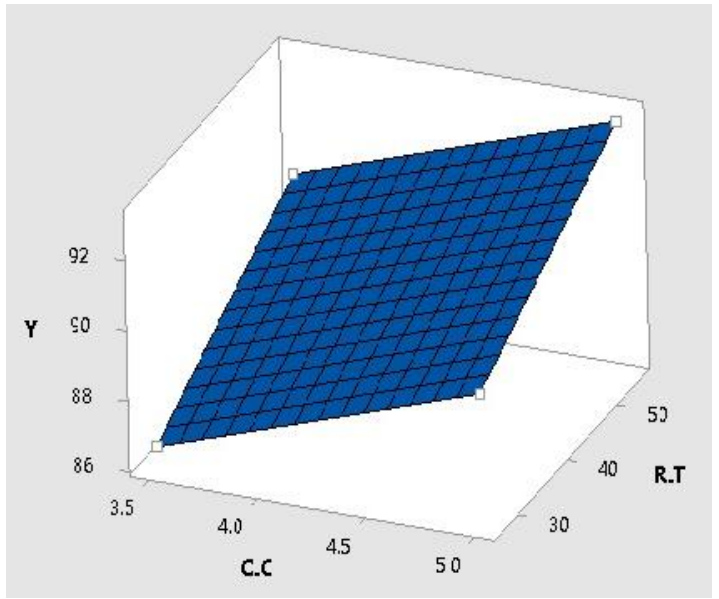

Figure 10. Surface Plot for max yield

\subsection{Model Validation}

Equation (Eq1) developed by regression analysis represents the theoretical yield. It is validated by conducting the experiments by using the three process parameters of methanol to oil ratio, catalytic concentration and reaction temperature. In order to achieve the accurate response yield, experiments were repeated for three times and the average yield was calculated as $95 \%$. The experimental yield result was in a reasonable agreement with the predicted yield results with an error of $1.230 \%$ which may acclaim as human error and can be neglected. Thus, from the experimental results it can be said that the definitive screening optimization is effective in predicting the important response parameters for the biodiesel production. 


\subsection{Glycerin to soap preparation}

The byproduct of transesterification process is the glycerin. In this research an attempt was made to utilize the glycerin by converting it to a soap for cleaning the glass beakers which are used in transesterification process. $250 \mathrm{ml}$ of solidified glycerin was heated up to $70^{\circ} \mathrm{C}$ to remove the methanol from the glycerin.10grams of $\mathrm{NaOH}$ was mixed with $62.5 \mathrm{ml}$ of hot water, this mixture was poured into liquid glycerin and it was allowed to mixed at slow speed. Essential oil (Lavender) was added for fragrance and the mixture was poured in a mold and it was allowed to cool for 8 hours. Figure 11 represents the flow chart of soap making.

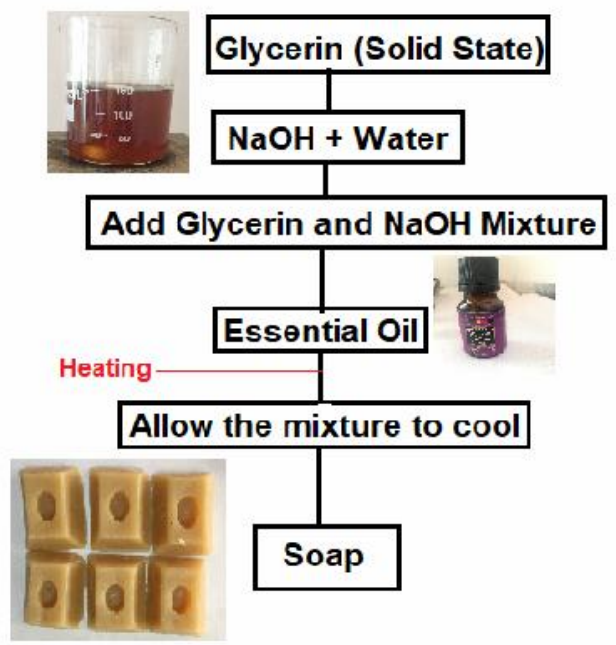

Figure 11. Flow chart of soap production

\subsection{Cost analysis}

The production cost of the biodiesel is mainly dependent on the raw oil cost and the catalyst which are used in the transesterification process. The present study focusses on the raw oil which is available abundantly after their usage. An internal survey was conducted in the college campus regarding the availability of oil after their usage. It is observed that around 85 liters of oil per day is dumped. Hence, the waste fried palm oil is used for the biodiesel production and the detailed cost involved in the process is shown in the Table 9. The cost of biodiesel is Rs 61.27/- which is lower than the present diesel cost of Rs 70/-.

Table 9. Cost calculations of waste fried palm biodiesel.

\begin{tabular}{lllll}
\hline S.No & Material Used & Quantity Used & Price/Liter/Kg & Rs \\
\hline 1 & Waste fried Palm oil & 1 liter & 0 & 0 \\
2 & Methanol & $260 \mathrm{ml}$ & 160 & 41.6 \\
3 & $\mathrm{H}_{2} \mathrm{SO}_{4}$ & $2 \mathrm{ml}$ & 35 & 0.07 \\
4 & $\mathrm{NaOH}$ & 8 grams & 450 & 3.6 \\
5 & Distilled water & 1 liter & 6 & 6 \\
6 & & & 51.27 \\
7 & Miscellaneous cost & & & 10 \\
8 & Total Cost of the WFPME & & $\mathbf{6 1 . 2 7}$ \\
\hline
\end{tabular}

\section{Conclusions}

In the present analysis, production of biodiesel from waste fried palm oil was investigated and optimized under the influence of three process parameters i.e. molar ratio, catalytic concentration and reaction temperature by definitive screening design. The obtained waste fried palm methyl was characterized to estimate its important fatty acid compositions, physical and chemical properties by following international standards. Based on the experimental results the following conclusions are illustrated.

- The experimental optimum process parameters were determined using definitive screening design were: molar ratio, catalystic concentration and reaction temperature with the corresponding yield of $96.230 \%$

- The molar ratio was observed to be most influencing parameter with a contribution factor of 6:1 followed by reaction temperature of $55^{\circ} \mathrm{C}$ and the least influence parameter was catalytic concentration.

- The regression model was developed and validated by confirmatory experiments at optimum conditions. 
- In order to achieve the accurate response yield, experiments were repeated for three times and the average yield was calculated as $95 \%$. The experimental yield result was in a reasonable agreement with the predicted yield results with an error of $1.230 \%$ which may acclaim as human error and can be neglected

- Fatty acid compositions were analyzed by gas chromatography and found that unsaturated fatty acid compositions were $59 \%$ followed by saturated fatty acid compositions of $41 \%$.

- The obtained methyl ester was characterized for different physical and chemical properties by following the international standards and the obtained results were closely matches with standard diesel fuel properties.

- The byproduct of transesterification process was glycerin and it was converted to soap.

- The cost analysis of waste fried palm biodiesel was low than the standard diesel fuel cost.

Hence, waste fried palm oil can be considered as most suitable for biodiesel production and it will reduce the initial raw oil cost of the oil during the transesterification process. Advanced optimization technique of definitive screening design was successfully tested and can be implemented.

\section{Nomenclature}

$\begin{array}{ll}\text { CC } & \text { Catalytic Concentration } \\ \text { CN } & \text { Cetane Number } \\ \text { DOE } & \text { Design of experiments } \\ \text { DSD } & \text { Definitive screening design } \\ \text { MR } & \text { Molar Ratio } \\ \text { RT } & \text { Reaction Temperature } \\ \text { WFPME } & \text { Waste frying palm methyl ester } \\ \text { WFPO } & \text { Waste frying palm oil }\end{array}$

\section{Acknowledgement}

The authors would like to thank Prof B V Appa Rao for his continuous support and Prof T V Hanumantha Rao Dean Academic Affairs, Prof B Naga Raju HOD for the kind assistance provided during this study.

\section{References}

Agarwal A K and Rajamanoharan K., 2007. Biofuels (alcohols and biodiesel) applications as fuels for internal combustion engines. Progress in Energy and Combustion Science, Vol.33, No 3, pp 233-71.

Bamgboye A.I and Hansen A.C., 2008, Prediction of cetane number of biodiesel fuel from the fatty acid methyl ester (FAME) composition. International Agrophysics, Vol 22, No. 1, pp. 21-29.

Cavalcante K.S.B., Penha M.N.C., Mendonça K.K.M., Louzeiro H.C., Vasconcelos A.C.S., Maciel A.P., de Souza A.G., Silva F.C., 2010. Optimization of transesterification of castor oil with ethanol using a central composite rotatable design (CCRD). Fuel, Vol 89, pp 1172-1176.

Demirbas A., 2005, Biodiesel production from vegetable oil by super critical methanol. Journal of Scientific \& Industrial Research, Vol 64, pp. 858-65.

Dhar A., Kevin R. and Agarwal AK, 2012. Production of biodiesel from high-FFA neem oil and its performance, emission and combustion characterization in a single cylinder DICI engine. Fuel Processing Technology, Vol.97, pp. 118-129.

Kolakoti A. and Rao B.V.A., 2017c. System and method for a supercharged IDI engine run by biodiesel. Indian Patent, No. 201741014482.

Kalam MA, Masjuki HH, Jayed MH, Liaquat, A.M, 2011. Emission and performance characteristics of an indirect ignition diesel engine fuelled with waste cooking oil. Energy, Vol36, pp 397-402.

Kolakoti A. and Rao B.V.A., 2017a. Performance and emission analysis of a naturally aspirated and supercharged IDI diesel engine using palm methyl ester. Biofuels. https://doi.org/10.1080/17597269.2017.1374770

Kolakoti A. and Rao B.V.A., 2017b, Effect of fatty acid composition on the performance and emission characteristics of an IDI supercharged engine using neat palm biodiesel and coconut biodiesel as an additive. Biofuels. https://doi.org/10.1080/17597269.2017.1332293

Kolakoti A. and Rao BVA, 2015. A comprehensive review of biodiesel application in IDI engines with property improving additives. I-manager's Journal of Mechanical Engineering, Vol.5, No 4, pp.35-45.

Modi, M.K., Reddy, J.R.C., Rao, B.V.S.K., Prasad, R.B.N., 2007. Lipase mediated conversion of vegetable oils into biodiesel using ethyl acetate. Bioresoure Technology. Vol 98, pp 1260-1264.

Rao KP and Rao BVA, 2017. Parametric optimization for performance and emissions of an IDI engine with Mahua biodiesel. Egyptian Journal of Petroleum, Vol 27, No.3, pp 733-743. 
Talamala V., Kancherla PR, Basava VAR and Kolakoti A, 2016. Experimental investigation on combustion, emissions, performance and cylinder vibration analysis of an IDI engine with RBME along with isopropanol as an additive. Biofuels, Vol.8, No.3, pp 307-321.

Vicente G., Martinez M., Aracil J., 2007. Optimization of integrated biodiesel production. Part I. A study of the biodiesel purity and yield. Bioresource Technology, Vol 98, pp 1724-1733.

Wu, W.H., Foglia, T.A., Marmer, W.N., Phillips, J.G., 1999. Optimizing production of ethyl esters of grease using $95 \%$ ethanol by response surface methodology. Journal of the American Oil Chemists' Society, Vol. 76, No 4, pp 517-521.

\section{Biographical notes}

Y. Rajesh and J. Bhargavi are the graduate students from Anil Neerukonda Institute of Technology and Sciences (A), Sangivalasa, Visakhapatnam, Andhra Pradesh, India in the year 2019.

Dr Aditya Kolakoti received MTech and Ph.D. from Andhra University College of Engineering (A), India in 2013 and 2017. He is an Assistant Professor in the Department of Mechanical Engineering, Anil Neerukonda Institute of Technology and Sciences (A). His research interests include Biodiesel production and Characterization, performance and emission analysis of DI and IDI diesel engines. He has published more than twenty research papers in reputed journals. He applied for one Indian Patent, has is a Associate Member in Institute of Marine Engineers, Institute of Engineers. He has conferred with Young Engineer Award 2018 from Institute of Engineers India. He has written few monographs related to his research work.

Mr B. G. Chandra Sekhar received MTech in Marine Engineering and Mechanical from Andhra University College of Engineering (A), India in 2015. He is a Assistant Professor in the Department of Mechanical Engineering, Anil Neerukonda Institute of Technology and Sciences (A). His research interests include computation fluid dynamics and thermal engineering.

Received February 2019

Accepted March 2019

Final acceptance in revised form March 2019 